\title{
Study on Pushover Analysis for High-rise Diaojiaolou on Multi-grade Steep Slope
}

\author{
Ning $\mathrm{Xu}^{1, \text { a }}$ \\ ${ }^{1}$ Shanghai Ershiye Construction Co., Ltd., Shanghai, China \\ a123xn@tongji.edu.cn
}

Keywords: multi-grade steep slope, high-rise, Diaojiaolou, Pushover, elastic-plastic.

Abstract. Based on the studies of necessity about seismic analysis for mountainous buildings, especially the high-rise Diaojiaolou in the southwestern region of China, a Pushover analysis for a real high-rise Diaojiaolou was carried out. It was shown that the displacement of the first floor of high-rise Diaojiaolou was larger than other floors', and the first floor structure was needed to be strengthened. Adding frame beams, reducing the slenderness ratio of the columns and strengthening reinforcement measures can enhance the vertical deformation capacity of the suspended feet. The plastic hinges of the upper structure of Diaojiaolou will change with the horizontal seismic force of the X-direction or Y-direction, and will change obviously along the height.

\section{Introduction}

Among the land resources that our country owns, mountain area occupies $2 / 3$ of the land area. The population of residence on mountainous occupies about half of the country's total population. With the development of urbanization in the western part of the country, mountainous buildings in the southwestern region have gradually increased. However, most mountainous regions in China are located in earthquake-prone zones. Due to the complexity and diversity of mountain terrain, more potential safety hazards will occur during the earthquake, which may lead to mountain collapse, landslides, mudslides and so on. Therefore, special attention must be paid to the seismic analysis of mountainous buildings.

Diaojiaolou is a special structural form in mountainous buildings [1]. The columns (or piles) with different lengths are used for erecting a platform on the slope [2]. With the platform, the building can be constructed safely. Because the high-rise Diaojiaolou is different from the lower-rise residential buildings and wood Diaojiaolou, the vertical structures of the high-rise Diaojiaolou are more irregular and the stiffness in different planes are uneven distribution, which have an impact on the seismic response of the structure inevitably. Therefore, being the unique characteristics of the high-rise Diaojiaolou, it should be noticeable at the stage of seismic design.

Using the static elastic-plastic method, Pushover analysis, the evaluation of anti-seismic performance for a real Diaojiaolou will be drawn in this paper. Many useful suggestions will also be given, and it will provide a reference for the implementation of post similar projects.

\section{Method of Pushover Analysis}

Pushover method is a new method widely used abroad in recent years for evaluating the seismic resistance of structures [3]. This method is a static non-linear calculation method essentially. Because of introducing the design response spectrum into the calculation process and the calculation results, the method is different from the previous methods of seismic static calculation.

The step of Pushover method is to apply some distributed horizontal force to the house according to the specific conditions of the house, then gradually increase the horizontal force so that the components of the structure will enter the stage of plasticity one by one. If some components entered into the plastic, the characteristics of the entire structure would change. So the size and distribution of horizontal forces can be adjusted accordingly. This condition alternates until the structure reaches the destruction of vertex, that is, becoming the mechanism or exceeding the limit of the displacement. 
This method is simple and practical, and it can be used for evaluating the seismic performance of the structure based on the seismic response spectrum.

\section{Project Overview}

The project named Wanshuo Jiangcheng Yipin in Chongqing, with a total construction area of approximately $142529 \mathrm{~m}^{2}$, has 19 single high-rise residences. The height of slope from top to bottom is about $80 \mathrm{~m}$. This project adopts partially framed shear wall structure with 21 floors above the ground and 7 floors below. The panorama of project and the construction photo of single Diaojiaolou are shown as follows.
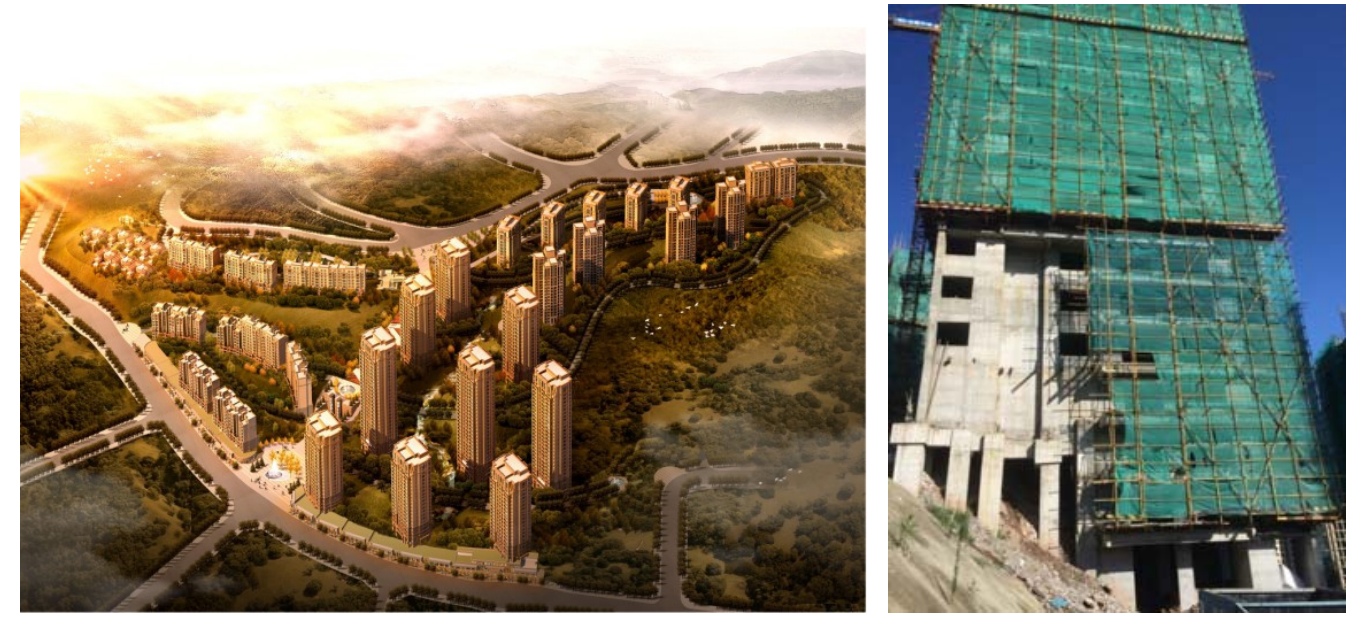

Fig.1 Project panorama

Fig.2 Construction scene of single Diaojiaolou

\section{Pushover analysis for the high-rise Diaojiaolou}

The Pushover analysis for the 21-floor Diaojiaolou was carried out by PKPM software. Firstly, the structural model must be established in the module of PMCAD [4]. Secondly, linear elastic analysis and reinforcement calculations should be carried out using the module of SATWE or PMSAP. After these two tasks, PUSH \& EPDA program for static elastic-plastic analysis can be started.

The results of the calculation are drawn as follows. Fig.3 gives the structural model of PMCAD, and Fig. 4 is the diagram of X-direction bending moment of the first floor extracted from the results of analysis.

It is easy to get the stress condition of the Diaojiaolou from the final model. Fig.5 is the mode 1 state of the Diaojiaolou, and Fig.6 is the main displacement, shear strain, displacement angle of main direction of the Diaojiaolou.

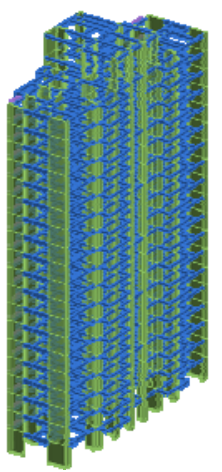

Fig.3 Structural model of PMCAD

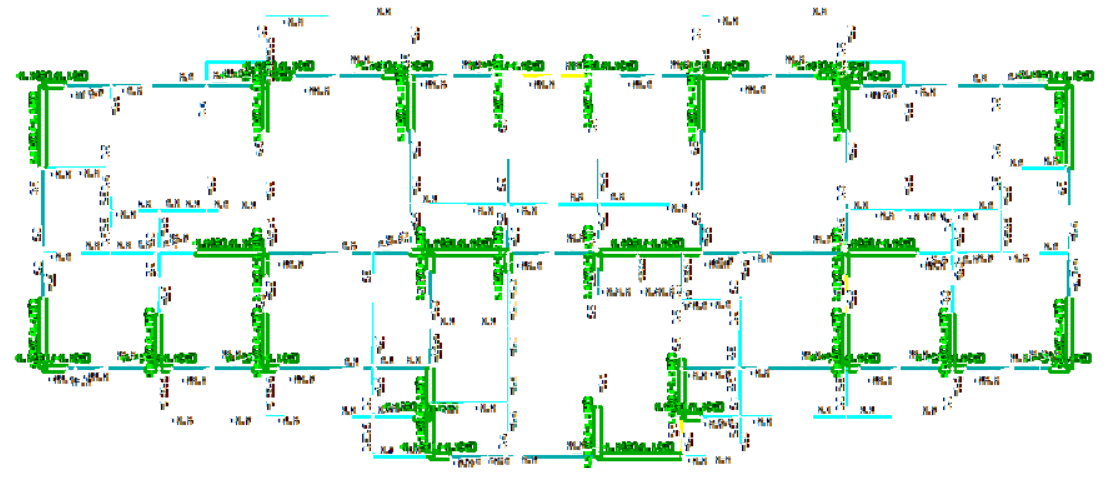

Fig. $4 \mathrm{X}$-direction bending moment of the first floor 

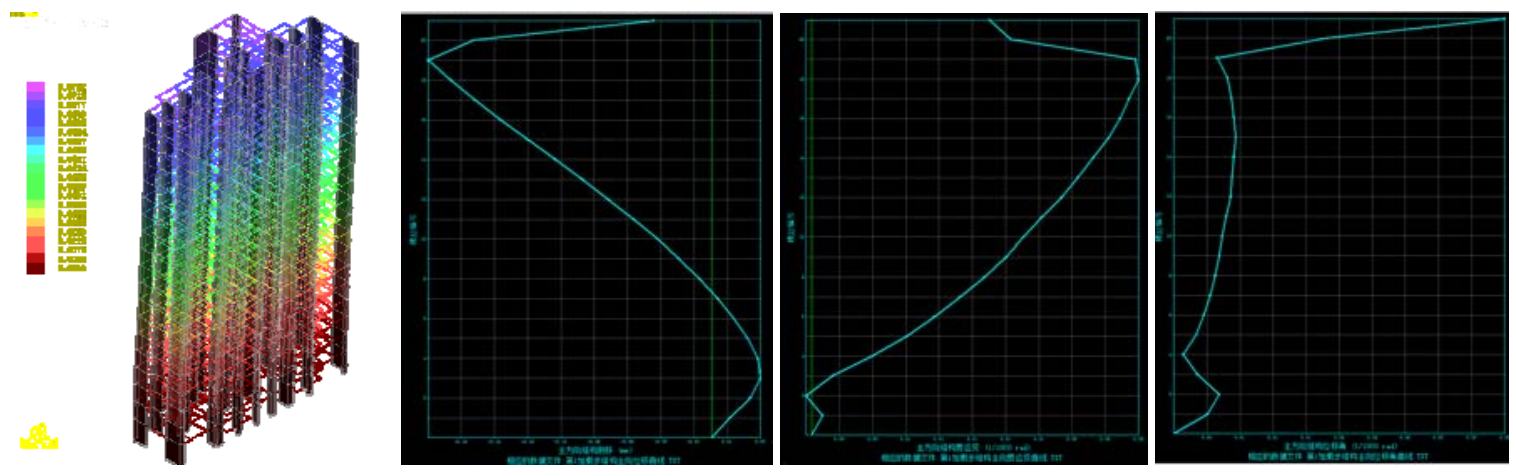

Fig.5 Mode 1 state

Fig.6 Main displacement, shear strain, displacement angle of main direction
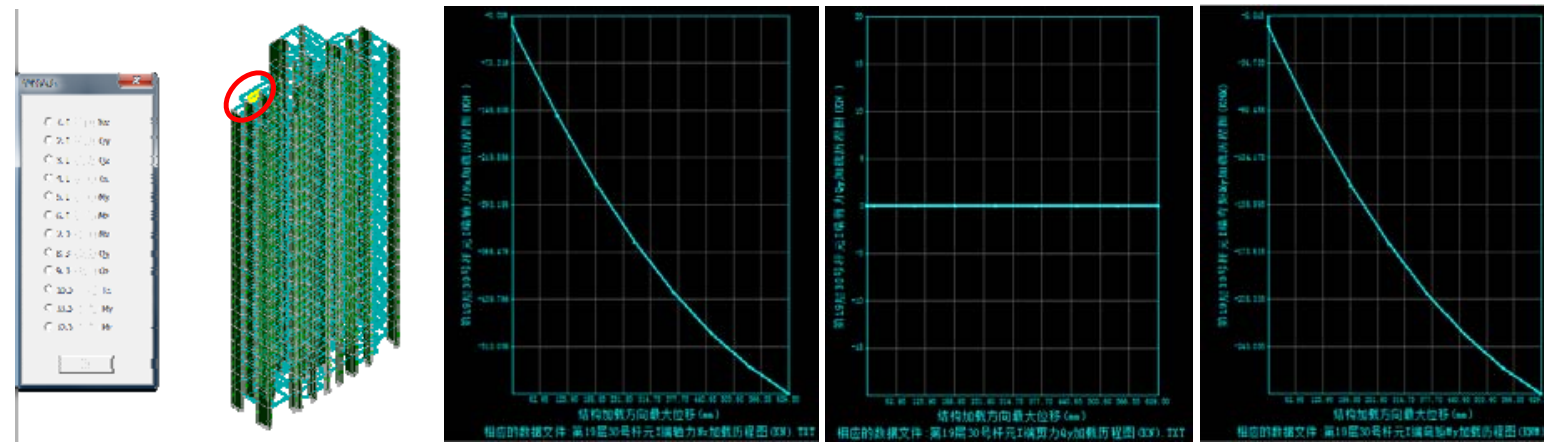

Fig.7 Designated component and its axial force, shear force, bending moment at the end of I

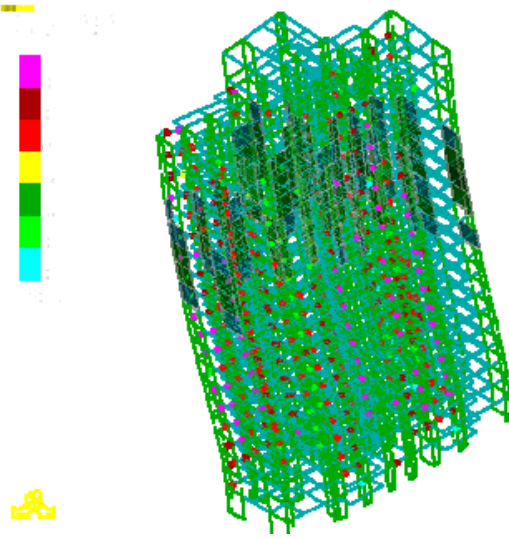

Fig.8 Distribution of Plastic hinge

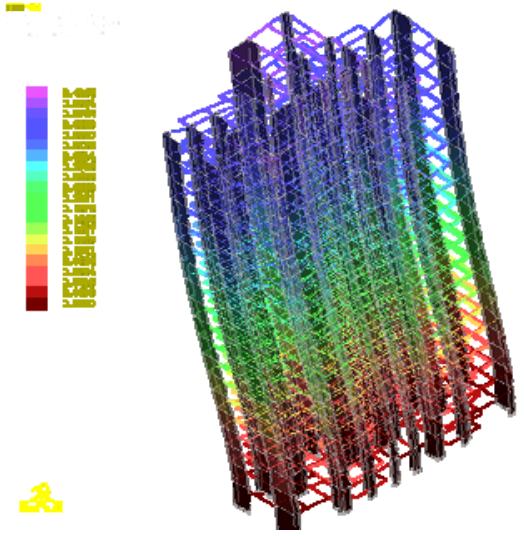

Fig.9 Structural deformation

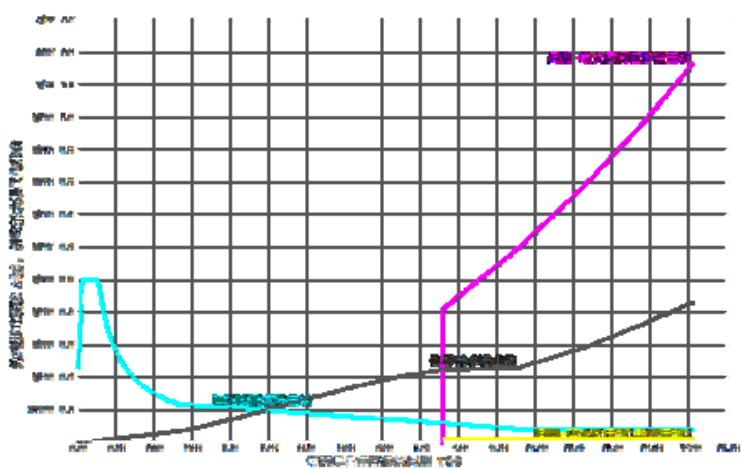

Fig.10 Performance curve 
Fig.7 describes a designated component in the upper left corner of the model. From the results of analysis, it is convenient to get the axial force, shear force, bending moment at both side of the end. Fig. 8 is the distribution of plastic hinge and Fig.9 is the structural deformation of the Diaojiaolou.

It is easy to get the performance point from the performance curve (Fig.10) of the Diaojiaolou. The performance point means the maximum nonlinear bearing capacity and maximum displacement the structure bearing when earthquake occurs [5]. The point within the control target performance range indicates that the structure meets the performance requirements.

\section{Conclusions}

1) Using the method of Pushover analysis, the change law of displacement of each floor and the vertical displacement of the suspending foot were obtained, which can contribute to the strengthen design of Diaojiaolou.

2) The displacement of the first floor of high-rise Diaojiaolou was larger than other floors'. Adding frame beams, reducing the slenderness ratio of the columns and strengthening reinforcement measures can enhance the vertical deformation capacity of the suspended feet.

3) The plastic hinges of the upper structure of Diaojiaolou will change with the horizontal seismic force of the X-direction or Y-direction, and will change obviously along the height. Plastic hinges in the section from B to IO can be quickly repaired.

\section{Acknowledgements}

This work is supported by Technology Fund of Shanghai Ershiye Construction Co., Ltd. (20170310). The author thank the project management team named Wanshuo Jiangcheng Yipin in Chongqing for their hospitability, time and opinions.

\section{References}

[1] G. Q. Gong, G. Xu: Structure Design of a Tall Diaojiao Building in Chongqing. Chongqing Architecture, Vol. 8 (2009), p.10-13.

[2] B. J. Lai, C. A. Xiao, B. Fu: Analysis of Seismic Torsional Effect on High-rise Building Structure of Unequal-height Fixed on Slope Land. Journal of Guizhou University (Natural Science Edition), Vol. 5 (2009), p.121-124.

[3] A. S. Elnashi: Advanced Inelastic Static (Pushover) Analysis for Earthquake Applications. Journal of Structural Engineering, Vol. 12 (2001), p.51-69.

[4] F. Wang, Z. Yang: Research on the Structure Design of Multistory Building on the Hillside. Journal of Central South University of Technology, Vol. 3 (2001), p.72-75.

[5] W. Z. Yuan, J. Li: The Example of Sloping Building Structure Design. Construction \& Design for Project, Vol. 12 (2009), p.11-14. 